\title{
Higher education internationalization and diplomacy: Successes mixed with challenges. A case study of Hungary's Stipendium Hungaricum scholarship program
}

\author{
LINH TONG*
}

Policy Analyst, Institute for Policy Studies and Media Development, VTC Online Building, 18 Tam Trinh Street, Hai Ba Trung District, Hanoi, Vietnam

\section{RESEARCH PAPER}

Published online: December 29, 2020

(C) 2020 The Author(s)

\begin{abstract}
This paper presents a case study of the Stipendium Hungaricum (SH) scholarship program and contributes to the existing body of knowledge on the characteristics, goals, and outcomes of governmentsponsored scholarship programs, which typically feature big players like the US, the UK, Germany, France, and China. The central research question is: "What are the stated goals and expected benefits of the SH from the perspectives of key stakeholder groups?" The study focused on three key stakeholder groups, namely: 1) The Hungarian government and the Vietnamese government; 2) Hungarian higher education institutions (HEIs) hosting Vietnamese scholarship recipients; and 3) Vietnamese SH scholarship recipients. Findings from this study suggest that the $\mathrm{SH}$ program is driven by three motives: diplomacy, human capital investment, and internationalization. Although internationalization appears to be the dominant goal, elements of diplomacy and human capital investment are indispensable, especially within the context of bilateral cooperation between Hungary and Vietnam. This purposeful combination has both positive and negative impacts. There is evident frustration among the Hungarian HEIs about the inclusion of Hungarian-language degree programs, which seems inconsistent with their internationalization strategy. Furthermore, there is a question about transparency in recruitment of SH scholarship recipients. The $\mathrm{SH}$ is an interesting case study to examine the dynamics of internationalization in
\end{abstract}

\footnotetext{
*Corresponding author. E-mail: tongkhanhlinh3594@gmail.com
} 
Hungarian higher education and the multiple roles of government scholarships sponsored by small/ middle-sized countries.

\section{KEYWORDS}

scholarship, diplomacy, international students, internationalization of higher education, student mobility, human capital investment

\section{INTRODUCTION}

Internationalization has become an inherent part of global education, especially higher education (Cheng, 2013). Millions of students travel across national borders every year to obtain higher education in foreign countries (Mazzarol \& Souter, 2002). According to UNESCO statistics, more than 5.3 million international students studied abroad in 2017, which is 2.65 times the number of 2 million in 2000 (UNESCO, 2019). In the absence of COVID's impacts, the volume of international student mobility would have reached 7.6 million in 2025 (Kim, 2010, p. 29). The United States, the United Kingdom, France, Germany, and Australia are traditionally the big players in the market of internationalized higher education, hosting half of the international student population (Oxford University, 2015, p. 5). However, these traditional destinations are "losing market share," (European Commission, 2013) because of a growing preference for intra-regional over inter-regional education exchanges and impressive achievements of several Asian countries in promoting themselves as attractive study destinations (Oxford University, 2015; UNESCO, 2014). The most celebrated cases in Asia include Japan, China, South Korea, India, and most recently Singapore and Malaysia (Oxford University, 2015; UNESCO, 2014).

While the literature on internationalization of higher education has made extensive analysis on these traditionally and emergingly popular countries, there is a big gap on less popular destinations. According to a typology study (Perna et al., 2014) about international scholarship programs, there were 183 international scholarship programs sponsored in higher education by national/federal governments of 196 nations. The reality is, thus, despite some countries being more popular than others as study destinations, majority of countries have their own internationalization agenda, which in sum constitute the other half of the international student mobility. It is interesting to question, for example, why the Laos government provides scholarships annually (VIED, 2017) for Vietnamese students to pursue higher education in Laos, given the country's low GDP and underdeveloped education system (EFA, 2015). There is no one-size-fits-all model of internationalization policy for higher education (Wit et al., 2015), and it is, therefore, necessary to investigate the dynamics shaping variations in internationalization policies across countries, popular or less popular.

The goal of this research is to contribute to this gap through a case study of the Stipendium Hungaricum Scholarship (SH) Program, which plays a central role in promoting the internationalization of Hungarian higher education (Dobos, 2017). Compared to Germany, France, the Netherlands, or Switzerland, Hungary is a middle-sized country in Europe with much less international popularity when it comes to the provision of higher education. Nevertheless, the Hungarian government has prioritized the Stipendium Hungaricum Scholarship program to 
bring thousands of international students annually to study for free at Hungarian higher education institutions. The Hungarian government also set an ambitious goal to "raise the number of incoming international students from 25,000 to 40,000 by 2021 (Higher education, 2017)." On the other hand, it is vital to perceive that the SH program is implemented strictly under the framework of inter-governmental bilateral cooperation, which involves elements of diplomacy. As a result, the $\mathrm{SH}$ program appears to be an interesting case study to examine not only the dynamics of internationalization in higher education, but also multiple pragmatic roles of government-sponsored scholarships.

Noticing this practical yet academically ignored importance of the $\mathrm{SH}$ scholarship program, this study explores the rationales underpinning the $\mathrm{SH}$ scholarship program and the benefits expected by the Hungarian government from international scholarship recipients. To better contextualize the program as a government-sponsored one under diplomatic cooperation, my study focused on the Hungarian-Vietnamese cooperation with regard to the SH program.

\section{LITERATURE REVIEW}

The internationalization literature considers internationalization as a means to adapt the national higher education system to globalization trends (Held, McGrew, Goldblatt, \& Perraton, 1999). A widely accepted definition of internationalization of HE describes it as "the process of integrating an international intellectual, or global dimension into the purpose, functions, or delivery of post-secondary education" (Knight, 2003). However, there is no one-size-fit-all model for HE's internationalization. In the existing literature, internationalization of $\mathrm{HE}$ is investigated at different levels of analysis (Knight, 2004). It can be considered as one strategy of a region (for example the Bologna process in the EU or the proposal to establish ASEAN Common space of HE (Yavaprabhas, 2009)), nation (i.e. Malaysia's ambition (Cheng, Mahmood, \& Yeap, 2013) to become education hub), or institution (Vavrus \& Pekol, 2015) (i.e. academic cooperation between two universities ( $\mathrm{Ng} \&$ Nyland, 2017) from two different countries) to adapt to globalization.

There are also different approaches to research on the internationalization of higher education. For example, Qiang (2003, pp. 250, 251) proposed four categories: activity approach, competency approach, ethos approach, and process approach. The "activity" approach looks at specific activities like academic exchange programs, curriculum development, recruitment of international students, or publication of online courses as subjects for research and focuses on analyzing international characteristics of those subjects. The "competency" approach tries to evaluate impacts of internationalization on the exchange of knowledge, improvement of academic qualifications, and advancement of intercultural skills. The "ethos" approach perceives internationalization as an inherent element in the identity of a region, a nation, or a university. As such, this approach applies organizational development theories to examine the creation of a culture or environment valuing international and intercultural perspectives within an identity under examination. The "process" approach considers internationalization as a comprehensive process with a combination of policies, procedures, and activities. Knight (2004), on the other hand, applied the systemic logics to differentiate between national or sector-level approach and institutional/provider-level approach. 
The explanation for rationales behind internationalization of HE also varies. Qiang (2003, pp. 252-254) summarized rationales in four categories: 1) political rationale emphasizes the soft power of higher education cooperation as a diplomacy tool, 2) economic rationale applies the logics of human capital theory to explain internationalization of $\mathrm{HE}$ as an investment to "the skilled human resources needed for international competitiveness of the nation, and where foreign graduates are seen as keys to the country's trade relations, or the direct economic benefits," 3) academic rationale sees internationalization as a means to achieve improvement of higher education quality, and 4) cultural and social rationale considers internationalization as a strategy to promote one country's culture and language.

Meanwhile, Stier (2004) offered a slightly different categorization of rationales into idealism, instrumentalism, and educationalism. Essentially, instrumentalist rationales refer to economic, diplomatic, and cultural/social functions (Qiang, 2003) of higher education cooperation while educationalism is almost the same as the academic rationale as described by Qiang (2003). The only difference lies in the category of idealism, which claims that higher education can foster "the creation of a more democratic, fair, and equal world."

Knight (2004) continued the systemic logics in her analysis of rationales and demonstrated variations of rationales for internationalization of HE. At the national level, Knight's descriptions of human resources development, strategic alliances, commercial trade, nation building, and social and cultural development as rationales for a nation's internationalization strategy shares many similarities with concepts proposed by Qiang and Stier. At the institutional level, Knight divided rationales into international profile and reputation, student and staff development, income generation, strategic alliances, research, and knowledge production (p. 2128).

Applications of these theoretical frameworks has flourished in the last decade as a result of the increasingly rapid growth of globalization. However, most of the research studies clustered around big and popular countries like the US, UK, Germany, France, Australia, Japan, and a number of other rising stars like China, Singapore, Malaysia. Hungary as a middle-sized country and a less famous study destination rarely becomes a topic of theoretical investigation. Apart from publications by the Tempus Public Foundation, other studies (Berács et al., 2016; Pusztai, 2008; Stefanyul, n.d.) related to internationalization of HE in Hungary focus entirely on analysing the influence of the Bologna process on Hungarian educational system in terms of student mobility, changes in degrees, credits, and qualifications, and emerging demands from the labour market.

Those conducted and published by the Tempus Public Foundation, which itself administers the SH program, offer evaluation of international students' impacts on Hungary's HE from an insider's perspectives. The study "Measuring the economic impacts of inbound higher education mobility" (Tempus Public Foundation, 2020) recognizes the positive impacts that the mobility of international students has exerted on the Hungarian economy at the local and systemic levels. This study attempts to draw a causal link between the increasing presence of international students and the subsequent changes in local consumption, direct payments, tourism, and studentification process in selected university cities in Hungary. The "International students in Hungarian Higher education institutions" study (Tempus Public Foundation, 2018a) presents a comprehensive insight into the internationalization processes and challenges of the Hungarian higher education, contrasting the quantitative against the qualitative aspects and the external against internal aspects of internationalization. The study outlines three phases of the Hungarian 
HE's internationalization. The first phase prioritizes quantitative indicators such as the number of foreign language courses, the rising inflow of foreign students, and the increase in quantity of English-teaching professors. The second phase targets creation of double degree programs or attempts to provide bilingual courses. The third phase attends to qualitative indicators such as content quality and multicultural environment. The study encourages the Hungarian HEIs to focus on improving HE quality to attract more self-financed international students, who can bring about revenues independent of the state funds.

However, it is difficult to separate impacts of the SH program as an intentional investment by the Hungarian government from those of the Erasmus+ as a regional program or fee-paying students. Therefore, whether or not the SH program has achieved its intended goal cannot yet be claimed. The only study that can be said to represent the SH population's opinions is the "Stipendium Hungaricum scholarship holders' expectations and attitudes" (Tempus Public Foundation, 2018b), which investigates expectations and attitudes of SH students after having experienced at least one semester at Hungarian HEIs. It asks SH students' evaluation of student services, teaching/learning quality, and reasons for choosing HEIs.

Nevertheless, none of these studies approach the $\mathrm{SH}$ as a government-sponsored scholarship program and analyze the $\mathrm{SH}$ as a diplomacy tool. All of these studies discuss about the $\mathrm{SH}$ program and the Hungarian HE's internationalization as if these initiatives had been welldesigned to meet goals respectively expected by key stakeholder groups. It seems there were no conflicts of interests among these fundamentally different stakeholder groups of the Hungarian government, the Hungarian HEIs, and the SH students. This is where the insider's perspective might have missed and why an outsider's observation is necessary (Dwyer \& Buckle, 2009). Moreover, the SH program is very unique in the literature for serving simultaneously as an internationalization program, a diplomacy tool, and an economic investment and would have great implications for other education initiatives from countries of similar conditions with Hungary (like countries in Central and Eastern Europe or countries in ASEAN). Only an outsider can analyze the SH program from these perspectives and that is where this research attempts to make contribution.

\section{THE STIPENDIUM HUNGARICUM SCHOLARSHIP PROGRAM}

The Stipendium Hungaricum Scholarship ( $\mathrm{SH}$ ) program is a government-sponsored scholarship program, in which the Hungarian government provides comprehensive financial support for international students to pursue higher education in Hungary. The SH program was established in 2013 with the declared mission of attracting talented international students to study in Hungarian higher education institutions (HEIs) and is implemented under the framework of inter-governmental bilateral cooperation. In the 2018-2019 academic year, 28 Hungarian higher education institutions participate in the SH Program, and more than 460 study programs are provided in foreign languages (414 in the English language). ${ }^{1}$ There are 5 main types of scholarships:

${ }^{1}$ See Call for applications 2018/2019, p. 8. Study in Hungary. Retrieved from http://studyinhungary.hu/static/upload/callfor-applications-2018-2019.pdf. 
1. Full degree bachelor studies

2. Full degree master studies

3. Full degree one-tier master studies ${ }^{2}$

4. Full degree doctoral studies

5. Partial studies ${ }^{3}$

The SH scholarships claim to cover full tuition fee; monthly stipend of HUF 40,460 for nondegree, bachelor, master and one-tier master level, or HUF 100,000 for doctoral level; accommodation in the form of dormitory or HUF 40,000; and year-round medical insurance. ${ }^{4}$ The SH Program functions exclusively under bilateral cooperation framework, in which the Ministry of Human Capacities of Hungary must have signed bilateral educational cooperation agreements with the partner's Ministry responsible for higher education. ${ }^{5}$ As a result, applications to the SH program are acceptable only after being nominated by the responsible authorities of the sending partner.

Vietnam has been a strategic sending partner of the $\mathrm{SH}$ program. Vietnam is one in ten sending partners that have SH cooperation in all five types of scholarships in the 2018-2019 academic year; $70 \%$ of other 50 sending partners have cooperation in maximum three scholarship categories. Vietnam International Education Cooperation Department (VIED) represents Vietnam's Ministry of Education and Training to monitor the SH program. Vietnamese students have opportunities to study in either English or Hungarian-taught programs under the SH framework. Moreover, the Vietnamese government is among a few national governments co-sponsoring the $\mathrm{SH}$ program with provision of a return ticket from Vietnam to Hungary, travelling expenditure, passport, visa fees, as well as $\$ 300$ (in addition to 40,000 forints granted by the Hungarian government) as a monthly input into living expenses of Vietnamese SH scholarship recipients. The level of the strategic partnership is also demonstrated in the number of $\mathrm{SH}$ scholarships offered to Vietnamese students, which doubled every two years. In 2014 and 2015, 50 scholarships were available for Vietnamese students (Anh, 2015). In the subsequent two years, the number increased to 100 per year (Tuan, 2017). Moreover, since 2018, 200 scholarships per year were made available to Vietnamese students. This is truly significant increase compared to the number of less than 10 Vietnamese students studying in Hungary during the country's break from the Soviet Union, ${ }^{6}$ exemplifying the importance of diplomacy in the SH program.

In addition to general requirements as specified on the SH official website, it is compulsory (on paper) for Vietnamese SH scholarship recipients to return to Vietnam to work for the Vietnamese government or the sending agencies (governmental ones). Vietnamese applicants can only register for one program, which is different from the encouragement of the TPF towards independent international applicants from other countries to register for three programs to increase the chances of being accepted (Call for applications 2018/2019, p. 9). Vietnamese undergraduate applicants are required to have at least 7.00/10.00 GPA (Vietnamese grading

\footnotetext{
${ }^{2}$ Ibid. An undivided master program that covers both the bachelor and the master levels of studies.

${ }^{3}$ Ibid. Short term training courses and practice, including study visits, in Hungarian or English language for groups of professionals in any field of interest.

${ }^{4}$ See 1.3. Provisions covered by the Scholarship (Call for applications 2018/2019, p. 6, p. 6).

${ }^{5}$ See 2.1. Eligible sending partners (Call for applications 2018/2019, pp. 6, 7).

${ }^{6}$ According to the interview with the representative from the Vietnamese Embassy in Budapest.
} 
system) during high school and the first semester of a Vietnamese university to be eligible for the program. Moreover, master and doctoral applicants must have been working for at least 12 months in a government agency and must not be older than 35 years by the time of application. Besides online submission to Stipendium Hungaricum website, Vietnamese applicants must submit online and hard-copy application documents to VIED. As a rule, each applicant must submit 200.000 VND (around \$9) application fee for the application to be considered by the Vietnamese side.

It is essential to notice the political background of such tight education cooperation. After important exchanges of state leaders' visits in 2017 and 2018, the bilateral relationship between Vietnam and Hungary was announced to have been raised to the level of "strategic partnership" (Cabinet Office of the Prime Minister, 2018). As can be interpreted from the political discourse of the Hungarian Prime Minister Viktor Orbán, Vietnam is a strategic partner in the Far East and an important component of Hungarian "Eastward Opening" foreign policy. The SH program repeatedly referred to as "the Hungarian state program," appears to be an indispensable steppingstone for enhancement of diplomatic relations between the two nations. While political and economic cooperation is the ultimate goal, it seems that diplomacy always starts with education and exchanges of students. The goodwill is illustrated in a statement by the General Secretary of the Communist Party of Vietnam - Nguyễn Phú Trọng - that, "Vietnam is striving to make good use of the Hungarian government's scholarship program.”.

\section{RESEARCH QUESTIONS}

The study does not attempt to either evaluate the SH program, or establish the causal relationship between the program and certain outcomes. Rather, it offers an exploratory study (Maxwell, 2013) investigating motivations underlying the SH program and benefits expected from key stakeholders. The SH program with a special focus on Hungary-Vietnam cooperation has been purposively selected as a case study to examine dynamics of higher education internationalization strategies of small/middle-sized countries and identify conflicts between internationalization and other purposes intended by governments of these countries, if any, by contrasting stated expectations and perceived benefits.

Consequently, the central research question was: "What is (are) the expected benefit(s) of the SH program from the perspectives of key stakeholder groups?" There were three key stakeholder groups under consideration: 1) the Hungarian government (represented by official published documents, the Tempus agency and governmental officials) and the Vietnamese government (represented by the education specialist at the Vietnamese Embassy in Hungary); ${ }^{7}$ 2) the Hungarian higher education institutions hosting Vietnamese scholarship recipients; and 3) Vietnamese $\mathrm{SH}$ scholarship recipients.

The intention was to compare and contrast the perceptions and expectations of these three stakeholder groups. Accordingly, the following sub-questions are specified:

\footnotetext{
${ }^{7}$ Although the Vietnamese government's perspectives are also taken into consideration, more focus will be on the Hungarian side because this is the program sponsored by the Hungarian government and the research wants to investigate how the Hungarian government expects to benefit from this generous investment.
} 


\section{Group 1:}

1. What are the rationales and expected outcomes of the SH Scholarship Program from the Hungarian/Vietnamese government's perspectives?

2. How does the Hungarian/Vietnamese government perceive benefits (so far) from the SH program?

\section{Group 2:}

1. What are the perceptions of Hungarian higher education institutions towards the rationales and expected benefits of the SH Program?

2. How do the institutions evaluate the program and the Vietnamese SH scholarship recipients?

\section{Group 3:}

1. Which are the most important factors influencing the Vietnamese students' decision to pursue higher education in Hungary? Is the SH scholarship the main reason?

2. How do studying experiences in Hungary contribute to students' academic performance, living experiences, and how do they affect students' perceptions/emotional ties to Hungary?

It is important to note that this study is practice-oriented. The author does not expect to make significant contribution by inventing an original definition of higher education internationalization or initiating theoretical adaptations. Instead, the study offers a careful observation into the interesting case study of the SH program. In other words, the main interest is to identify challenges, if any, arising from conflicting expectations of key stakeholders and provide relevant recommendations to mitigate the so-called unintended consequences of government policies and investments (Wihlborg and Robson, 2017), which is Hungary's internationalization policy and investment in higher education in this case. This interest shapes the research questions and is coherently integrated in the research methodology as well as results' interpretations.

\section{METHOD}

In order to answer the research questions, I analyzed relevant policy documents and conducted in-depth interviews with relevant stakeholders. The study applies a purposive, theoretically driven data collection methodology (Yin, 2003a, 2003b) to explore how expected benefits from a government-sponsored international scholarship program may vary depending on Hungary's national context and diplomatic relations. Although this study features the SH program within the Hungary-Vietnam diplomatic context, the results and recommendations can apply to other similar government-sponsored programs either within or outside Hungary (Maxwell, 2013). Most directly, the results and recommendations may be applicable to SH's other strategic partners such as countries of the former Soviet Union or countries as important to Hungary's diplomatic missions as Vietnam.

Drawing on review of relevant literature, the author designed data collection protocols, collected, triangulated, and analyzed data from various primary sources for comparison purpose (Yin, 2003a). Data collection was divided into two main stages.

At the first stage, the author analyzed existing primary documentation to obtain preliminary understanding of the SH program. This involves documents concerning/mentioning/guiding the 
SH program as available on the website of the Tempus Public Foundation, which has been administering the SH program (https://tka.hu/english), the Stipendium Hungaricum website (https://stipendiumhungaricum.hu/), and the Study in Hungary website (http://www. studyinhungary.hu/).

The author requested the raw data of Vietnamese scholarship recipients' responses to two surveys conducted by the Tempus Public Foundation in 2017 to obtain background information about Vietnamese students in Hungary. One is the Student Satisfaction Survey (Summer 2017), which aims to investigate students' perceptions and attitudes towards Hungary, Hungarian educational services, as well as identify the factors dissatisfying students. For this survey, the Tempus Public Foundation shared an excel file of 166 responses from Vietnamese SH scholarship holders. The other is the Applicant survey (Spring 2017), which examines application process, access to information, and motivations of international students to pursue higher education in Hungary. There are, however, only 42 responses from Vietnamese SH scholarship recipients in this survey.

At the second stage, the author conducted semi-structured interviews with representatives of three key stakeholder groups as listed above. Based on the initial analysis of Tempus database of Vietnamese students, the author selected HEIs hosting the largest number of Vietnamese students for interviews. As for selection of Vietnamese students, the author tried to guarantee the representativeness in terms of gender (females versus males), HE levels (BA, MA, PhD), geography (inside versus outside Budapest), and study fields (social sciences vs natural sciences). This strategy is to ensure the findings are as generalizable as possible (Fig. 1).

The first round of interviews was conducted between November 2017 and January 2018 with 9 individuals. Analyses of these interview scripts advised the next round of interviews between February 2018 and May 2018. Interviews were conducted in Vietnamese for Vietnamese students and the Vietnamese Embassy and in English for all other stakeholders. All interviews were audio-recorded with pre-signed consent form and transcribed in English language.

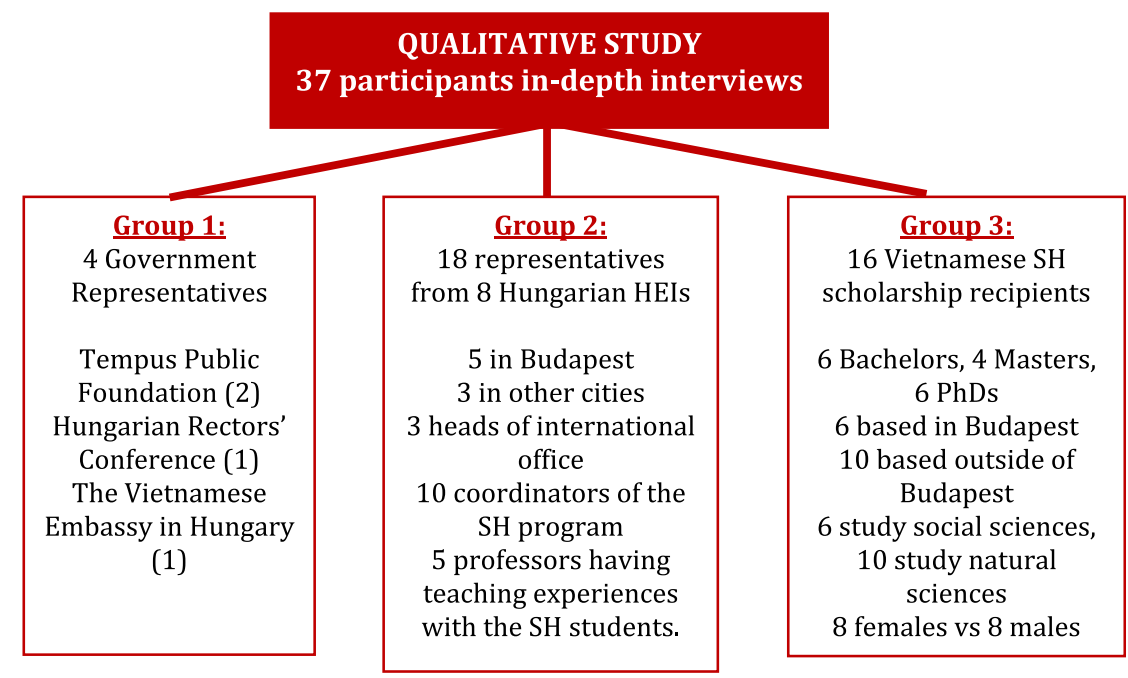

Fig. 1. The qualitative study 
A database including official documents, reports, and interview transcriptions was established to ensure coherence and reliability of the analyses (Yin, 2003b). The author applied QDA software $^{8}$ to design the code book and compile data into the three stakeholder groups. A primary list of codes was developed based on reviews of relevant literature. This list was continuously updated whenever a new theme emerged under supervision of the professor and discussions with other colleagues. Codes were carefully adapted for the other stakeholder groups to reflect diverging perceptions. There was a constant process of spotting emerging themes, validating those that overlap, and adjusting the data into broader themes. Data from different categories was triangulated against each other, SH's survey data, and the literature to ensure coherence and trustworthiness of interpretation strategies (Maxwell, 2013, p. 128).

In this study, analyses of the interviewed data and documents focused on exploring the political, economic, academic, cultural, and social rationales (Qiang, 2003) that program funders, HEIs, and program participants associated with the $\mathrm{SH}$ program. Text analysis with the help of QDA Miner program was applied to identify existing discourses on the rationales and expected outcomes of the $\mathrm{SH}$ program.

\section{RESULTS}

This section reports the results of qualitative analysis from official documents and in-depth interviews. Because the $\mathrm{SH}$ is initiated and sponsored by the Hungarian government, this analysis was based on the Hungarian perspective, putting aside rationales and expected benefits from the Vietnamese side.

\section{Rationales of the Stipendium Hungaricum Scholarship program}

The SH program has three important missions: 1) to support Hungary' foreign policies, 2) to internationalize Hungarian Higher Education system, and 3) to stimulate economic development through investment in the education sector (Table 1).

\section{SH as a diplomacy tool}

From the perspective of the Hungarian government, the $\mathrm{SH}$ program is expected to enhance the soft power of Hungary outside the EU through education cooperation. The program sees

Table 1. Contrasting priorities between 2 key stakeholders

\begin{tabular}{lcc}
\hline Rationales/expected benefits & Hungarian government & $\begin{array}{c}\text { Hungarian Higher Education } \\
\text { Institutions (HEIs) }\end{array}$ \\
\hline Diplomacy & 1st priority & Not as important \\
Internationalization & High priority & st priority \\
Human Capital/Economic Investment & High priority & High priority \\
\hline
\end{tabular}

${ }^{a} 1$ st priority simply means the most important. On the scale of three, the 1 st priority receives $3 / 3$, the high priority receives $2 / 3$, and the not as important receives $1 / 3$.

\footnotetext{
${ }^{8}$ Free version can be downloaded at https://provalisresearch.com/products/qualitative-data-analysis-software/.
} 
international students as "future ambassadors," who can represent Hungarian interests in their respective countries. Emphasis on education cooperation's soft power is felt and applied even among Hungarian HEIs, although diplomacy is not their utmost concern.

\begin{abstract}
"One of the South African ministers told us, as we gathered for him the South African students at our university, that "I expect that you are good students here, and you are ambassadors of South Africa." and I said that "We also expect that when you go back home, you will be good ambassadors of Hungary in South Africa" - A representative from Corvinus University
\end{abstract}

Promotion of Hungarian language and culture is another essential component of the diplomatic mission of the $\mathrm{SH}$ program, especially with the provision of Hungarian-taught programs for foreign students. Representatives from the Tempus Public Foundation and the Vietnamese Embassy in Hungary stressed on the essence of increasing the number of Vietnamese students pursuing Hungarian-taught programs, who are expected to serve as diplomatic links between Vietnam and Hungary in the future.

"Towards a partner country like Vietnam, Hungary is proud to have a Vietnamese community, which does not hold Hungarian citizenship, but can still speak Hungarian language and understand Hungarian culture. This is a foundation for a long-standing diplomatic relationship." -A representative from the Tempus Public Foundation.

\title{
$\mathrm{SH}$ as a driver for Internationalization of Hungarian HE
}

Internationalization is named as a key objective of the $\mathrm{SH}$ program for both the Hungarian government and Hungarian HEIs. The stated goal of the program is to increase competitiveness of Hungarian $\mathrm{HE}$ in the international arena through: 1) improving quality of Hungarian $\mathrm{HE}$ services; 2) strengthening international cooperation of Hungarian scientific community and global visibility of Hungarian HE through attraction of top talents to enlarge Hungarian scientific network; and 3) diversifying teaching, learning, and working environments in HEIs in adaptation to increasing presence of international students.

"Internationalization is becoming an essential part of the development strategies of Hungarian HEIs"

Representative of the Hungarian Rectors' Conference

"The aim of the government is to raise the number of incoming international students from 25,000 to 40,000 by 2021." (Higher education, 2017)

One measurement of internationalization success was the impressive increase in the numbers of sending partners and available slots for international applicants (Fig. 2).

Another measurement of internationalization success is the rapid development and professionalization of international offices located at Hungarian HEIs participating in the $\mathrm{SH}$ program. All interviewed universities appreciated that international experiences are felt at all levels and benefit everyone thanks to the presence of international students sponsored by the SH program.

"We have to develop things very fast to institutionalize student services for the international students and build up all these work loads within the university. We renewed the university website, the English pages, the content; we created much content compared to what we had in 2012, and now much more." Representative of ELTE 


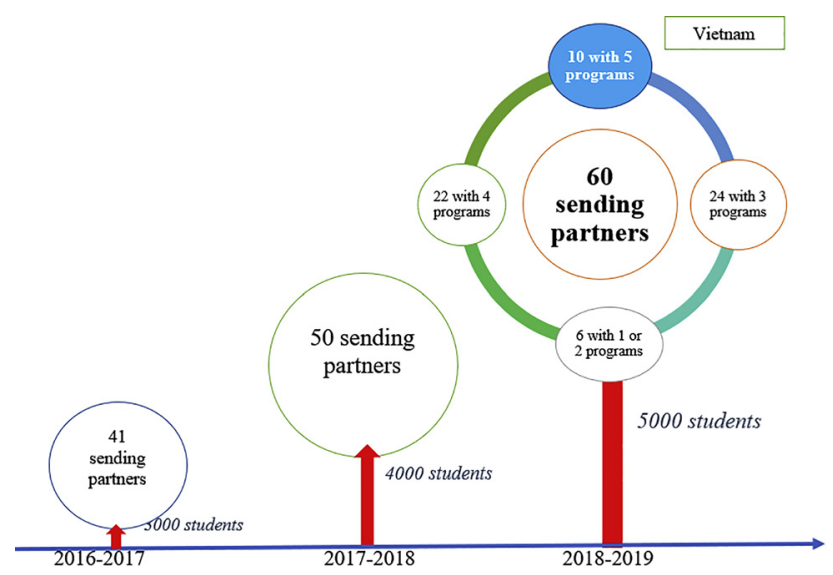

Fig. 2. Increasing numbers of $\mathrm{SH}$ sending partners and available application positions

"It comes with the increasing number of international students, that is something that everybody experiences here at the university at all levels. Starting from the receptionist at the door of the building... Also, the teachers have international students there, so they have to adjust their teaching materials into English." A representative of Obuda University

\section{$\mathrm{SH}$ as an economic investment}

Presence of international students is also expected to contribute positively to economic development in different regions of Hungary.

"I talked to some guy from Debrecen who said during a few years, it has been a spectacular scene, how the presence of international students improved the life of the city, like very good-quality of restaurants, and good night clubs, , cafés, cultural events." A representative from Hungarian Rectors' Conference

Furthermore, international students are expected to share with colleagues and friends their experiences with Hungarian HE system so that more self-paying students will be convinced to study in Hungary. Graduate students of the SH program are seen as essential links, who can support the promotion of Hungary's international economic and academic cooperation in their respective countries.

\section{DISCUSSION}

\section{Existing challenges}

The mystery of the Hungarian-taught programs. Results from my study indicate that there is clear frustration among the Hungarian HEIs about the inclusion of Hungarian-language degree programs in the SH scholarship scheme. This is a core conflict between the Hungarian 
government's priority to enhance diplomatic connections and the Hungarian HEIs' preference for improvement of English programs for internationalization purpose.

Representatives of Hungarian HEIs. All representatives of universities expressed concerns about Hungarian language proficiency of students and suggested the need to tighten control over language requirement to ensure better quality. Two out of eight interviewed universities had already stopped receiving foreign students studying in the Hungarian language in 2016. Both Hungarian professors and Vietnamese students confirmed that 1 year at the Balassi Institute is undoubtedly insufficient to prepare foreign students for the Hungarian academic learning environment.

Vietnamese SH scholarship recipients. Almost all interviewed students said that they had enthusiastically encouraged their peers to apply to study in Hungary in English-taught programs, but always hesitated to recommend programs in the Hungarian language. The difficulty of the Hungarian language negatively influenced the academic performances of Vietnamese students.

"I usually joked with my Hungarian friends that I am just one-year-old child when it comes to the Hungarian language" - One Vietnamese student said.

On average, those studying in English programs obtain much better results (4/5 or 5/5) than those studying in Hungarian programs (2/5 or $3 / 5)$. Those Vietnamese students studying in Hungarian-taught programs said they understood at most $50 \%$ of the lessons, and many had to extend graduation deadlines. When asked about the reason for choosing to study in the Hungarian language, all interviewees said "I know Hungarian is a difficult language before coming here. But I did not know that it would be so difficult."

Improvement of education quality to ensure the sustainable success of the SH. Interviews with Vietnamese students revealed that Hungarian education does not meet expectations about a European-standard system. Most Vietnamese students find teaching methodologies in Hungary very similar to that in Vietnam, focusing on memorization and theories, while they had expected more interactive and creative learning. Advantages of Hungarian education compared to Vietnamese education include access to more advanced technologies and professors' expertise in conducting scientific research. Nevertheless, these two advantages alone are not sufficient to convince foreign students of the quality of Hungarian higher education so that they could confidently recommend their colleagues and peers at home to self-finance studying in Hungary.

In short, having SH scholarships remains the key attraction of the Hungarian HE, which is not sustainable in the long run. The eventual goal of the $\mathrm{SH}$ program is to provide initial support for Hungarian HEIs to internationalize and modernize until "institutions are more able to stand on their own," meaning this support cannot be forever. Thus, all the above-mentioned achievements with increasing numbers of international applicants and institutional developments should be only regarded as the very first preparation stage of the SH program. It is high time to re-evaluate the missions of the $\mathrm{SH}$ and schedule plans for the next step to improve quality and competitiveness of Hungarian Higher Education program through maximizing benefits of having international students sponsored by the $\mathrm{SH}$. 


\section{Recommendations}

Overall, the Stipendium Hungaricum Scholarship program is a success story from the perspectives of Diplomacy and Human Capital/Economic Investment. In-depth interviews with key stakeholders and beneficiaries of the SH shed light on significant accomplishments as well as remaining challenges in the Internationalization objective of the program. The Hungarian government and Hungarian HEIs - two key stakeholders of the $\mathrm{SH}$ - should consider the following recommendations:

1. Recommendations for the Hungarian-taught programs

1.1. Increase the length of time and preparation intensity for the Hungarian language

Vietnamese students wishing to study in Hungarian-taught programs should be required to start learning the Hungarian language from the second semester of their first year studying in Vietnam. Furthermore, during the studying period at Balassi Institute, students must be required to participate weekly in one standard lecture at other universities so that they can understand the language challenge and have the motivation to study harder.

1.2. Offer additional incentives for foreign students studying in Hungarian-taught programs

Since the Hungarian language is challenging yet very important for both Vietnamese and Hungarian governments, offering additional incentives for students studying in the Hungarian language is necessary. Incentives can be higher financial support or guaranty of employment opportunities after graduation.

\subsection{Limit Hungarian-taught programs for foreigners to certain specializations}

The Hungarian government should prioritize offering scholarships for international students willing to specialize in Tourism, Hungarian studies, Hungarian language, Hungarian literature, which directly relate to the Diplomacy objective of the program.

2. A framework to improve education quality

2.1. Improve international students' qualifications

The SH committee should consider lending universities more power in recruiting international students that meet their requirements and expectations. In doing so, the SH committee should also step by step initiate negotiations with the sending partners to enable the selection process to take into account universities' analysis and evaluation.

"All universities would like to understand requirements or evaluations points or viewpoints from sending countries. Sometimes we do not understand why students got the scholarship positions or status from the Tempus despite the results of analysis from our side." One Hungarian HEI representative

"In the global market, our SH scholarships are not so competitive. Moreover, I think the name of this scholarship is not so good because the amount of money is delivered independently from the performance." One Hungarian HEI representative

Furthermore, the requirement to maintain scholarship positions should be tightened so that students have more pressure to study well and make meaningful contributions to Hungarian teaching and studying outcomes. 


\subsection{Improve universities' performances}

As a result of the Tempus's publication of a student satisfaction survey, one interviewed university launched an investigation to reassess international students' satisfaction and quickly made plans to improve students' services. This demonstrates necessity and effectiveness of having a transparent evaluation mechanism so that universities will be put into competition with each other and thus motivated to work harder for improvement of education quality.

Furthermore, the government should sponsor more channels and events for HEIs to exchange and discuss internationalization experiences and strategies as well as provide greater support for less popular universities (outside Budapest) and academic programs (like Environmental Science) to improve the baseline for academic competition.

\section{CONCLUSION}

The findings from this study offer interesting insights into conclusions drawn from those conducted by the Tempus Public Foundation. Hosting the largest number of Vietnamese students, the HEIs in this study have mostly completed the first phase of internationalization with evident quantitative achievements in terms of foreign language courses, inflow of foreign students, and professors' English teaching qualifications. Nevertheless, these HEIs have been struggling to improve education quality and provide students with multicultural environments to attract more fee-paying students. Under such contexts, the diplomacy element of the program as represented in the provision of Hungarian-language courses appears an additional challenge. The diplomacy goal also presents inherent conflicts of interests across the three key stakeholders, which cannot be spotted from the insider perspective of the Tempus Public Foundation or other Hungarian scholars.

The conflict between diplomacy and internationalization would not have been that vivid had the national language been English, German, French, or Chinese. This conflict is more intense for a middle-sized country like Hungary. On one hand, Hungarian HE has relatively good academic standards and wants to attract self-financing students. On the other hand, few international students want to study in Hungarian, and this does not help internationalization of Hungarian HE. For a small country like Laos, for example, the diplomacy priority would prevail and there would be less disagreement as a result.

While Hungarian language is good for diplomacy, for a middle-size country having ambition of attracting more self-financing students like Hungary, it comes as a cost as it does not have impacts on institutional internationalization, which is the utmost priority for HEIs as well as the government's education strategy in general. Thus, there must be strategies to ensure the diplomacy goal does not inhibit other expected benefits, especially internationalization of higher education, of the SH program.

This dilemma is not unique to Hungary. Other middle-sized countries with similar bilateral relationships might share experiences and learn from the case of the SH program. The key is to balance different goals across different stakeholder groups.

Ethics: The study procedures were carried out in accordance with the Declaration of Helsinki. All subjects were informed about the study and all provided informed consent. 
Funding sources: No financial support was received for the study.

Authors' contribution: I am solely responsible for this research paper. I take responsibility for the integrity of the data and the accuracy of the data analysis.

Conflict of interest: The authors declare no conflict of interest.

\section{ACKNOWLEDGEMENT}

I would like to express my deepest gratitude towards Professor Kata Orosz for her kind support and insightful guidance throughout the conduct of the project. I also would like to extend my thanks to Dr. Gergely Kovats and Dr. Matyas Szabo for their kind encouragement so that I can complete the research paper. I am also grateful for the opportunity to participate in the CEHEC Conference to learn from other experts and obtain constructive recommendations on the paper.

\section{ABOUT THE AUTHOR}

Linh Tong received her MA honor of Public Administration from the Central European University in 2019. Previously, she was pursuing BA in International Studies at ADA University in Azerbaijan. Linh deeply cares for education and wants to advocate for extensive education reforms in Vietnam, her home country. Linh is now working as a policy analyst at the Institute for Policy Studies and Media Development. She is currently undertaking a study on how to integrate digital safety skills into the formal education system in Vietnam.

\section{REFERENCES}

\section{Journal article:}

Cheng, M. Y., Mahmood, A., \& Yeap, P. F. (2013). Malaysia as a regional education hub: A demand-side analysis. Journal of Higher Education Policy and Management, 35(5), 523-536. https://doi.org/10.1080/ 1360080X.2013.825412.

Dwyer, S. C., \& Buckle, J. L. (2009). The space between: On being insider-outsider in qualitative research. International Journal of Qualitative Methods, 54-63. Retrieved from https://doi.org/10.1177/ 160940690900800105.

Knight, J. (2003). Updating the definition of internationalization. International Higher Education, 33. https://doi.org/10.6017/ihe.2003.33.7391.

Knight, J. (2004). Internationalization remodeled: Definition, approaches, and rationales. Journal of Studies in International Education, 8(1), 5-31. https://doi.org/10.1177/1028315303260832.

Maxwell, J. A. (2013). Qualitative research design. An interactive approach (3rd ed.). Los Angeles: Sage. 
Mazzarol, T., \& Souter, G. N. (2002). 'Push-Pull' factors influencing international student destination choice. The International Journal of Educational Management, 16, 82-90. https://doi.org/10.1108/ 09513540210418403.

Ng, J., \& Nyland, B. (2017). Critical examination of internationalisation: A case study of a collaboration between an Australian and a Chinese university. European Journal of Higher Education, 1-15. https:// doi.org/10.1080/21568235.2017.1388186.

Perna, L. W., Orosz, K., Gopaul, B., Jumakulov, Z., Ashirbekov, A., \& Kishkentayeva, M. (2014). Promoting human capital development: A typology of international scholarship programs in higher education. Educational Researcher, 43(2), 63-73.

Pusztai, G. (2008). The Bologna process in Hungary. European Education, 40(2), 85-102. https://doi.org/10. 2753/EUE1056-493440020X.

Qiang, Z. (2003). Internationalization of higher education: Towards a conceptual framework. Policy Futures in Education, 1(2), 248-270. Retrieved from http://journals.sagepub.com/doi/pdf/10.2304/pfie.2003.1.2. 5.

Stier, J. (2004). Taking a critical stance toward internationalization ideologies in higher education: Idealism, instrumentalism and educationalism. Globalization, Societies and Education, 2(1), 83-97. https://doi. org/10.1080/1476772042000177069.

Vavrus, F., \& Pekol, A. (2015). Critical internationalization: Moving from theory to practice. Dialogues on Global Dimensions of Education, 2(2), 5-21. Retrieved from http://preserve.lehigh.edu/fire/vol2/iss2/2.

Wihlborg, M., \& Robson, S. (2017). Internationalisation of higher education: Drivers, rationales, priorities, values and impacts. European Journal of Higher Education, 8(1), 8-18. https://doi.org/10.1080/ 21568235.2017.1376696.

Yin, R. K. (2013a). Applications of case study research, Applied social research methods series (2nd ed., Vol. 34). Thousand Oaks, CA: Sage Publications.

Yin, R. K. (2013b). Case study research: Design and methods, Applied social research methods series (3rd ed., Vol. 5). Thousand Oaks, CA: Sage Publications.

\section{Book chapter:}

Held, D., McGrew, A., Goldblatt, D., \& Perraton, J. (1999). Global transformations: Politics, economics and culture. In D. Held, A. McGrew, D. Goldblatt, \& J. Perraton (Eds.), Global transformations: Politics, economics, and culture (pp. 14-28). Stanford: Stanford University Press.

Kim, Y. C. (2010). The Asia Pacific education market and modes of supply. In C. C. Findlay, \& W. C. Tierney (Eds.), Globalization and tertiary education in the Asia-Pacific: The changing nature of a dynamic market (pp. 17-39). Singapore: World Scientific.

\section{Online document:}

Anh, L. (2015). Hungary tăng gấp đôi số học bổng cho sinh viên Việt Nam (Hungary doubles the amount of scholarships awarded to Vietnamese students). Dantri. Retrieved from http://duhoc.dantri.com.vn/duhoc/hungary-danh-100-suat-hoc-bong-cho-hoc-sinh-sinh-vien-viet-nam-20151222173343232.htm. 
Tuan, D.. (2017). Hungary sẽ tăng học bổng cho sinh viên Việt Nam (Hungary will increase the amount of scholarships for Vietnamese students). Baochinhphu. Retrieved from http://baochinhphu.vn/Doi-ngoai/ Hungary-se-tang-hoc-bong-cho-sinh-vien-Viet-Nam/316439.vgp.

\section{Program documents:}

Call for applications. (2018/2019). Study in Hungary. Retrieved from http://studyinhungary.hu/static/ upload/call-for-applications-2018-2019.pdf.

Higher education. (2017). Retrieved from http://studyinhungary.hu/study-in-hungary/menu/studying-inhungary/higher-education.html.

VIED (Vietnam International Education Cooperation Department, Ministry of Education and Training). (2017). Thông báo tuyển sinh đi học tại CHDCND Lào năm 2017 (Announcement to recruit students to study in Lao People Democratic Republic in 2017). Retrieved from http://vied.vn/vi/tin-tuc/tuyen-sinh/ 910-thong-bao-tuyen-sinh-di-hoc-tai-chdend-lao-nam-2017.html.

\section{Report:}

Berács, J., Derényi, A., Kádár-Csoboth, P., Kováts, G., Polónyi, I., \& Temesi, J. (2016). Hungarian higher education 2016 strategic progress report. Center for International Higher Education Studies, Budapest. Retrieved from http://unipub.lib.uni-corvinus.hu/2828/1/Strat_progress_Report_Hungary_2016.pdf.

EFA (Education for All). (2015). Country report of Lao People's democratic Republic. Education for all 2015 National Review. Retrieved from http://unesdoc.unesco.org/images/0023/002314/231489e.pdf.

European Commission. (2013). Communication from the commission to the European Parliament, the council, the European economic and social committee, and the committee of the regions: European higher education in the world. Retrieved from http://eur-lex.europa.eu/legal-content/EN/ALL/? uri=CELEX:52013DC0499.

Oxford University. (2015). International trends in higher education 2015. University of Oxford International Strategy Office. Retrieved from https://www.ox.ac.uk/sites/files/oxford/International\%20Trends\% 20in\%20Higher\%20Education\%202015.pdf.

Stefanyul, H. (n.d). The Bologna process and its influence on the system of higher education in Hungary and in Ukraine. Retrieved from http://portal.zmne.hu/download/bjkmk/bsz/bszemle2006/4/Stefanyuk. pdf.

Tempus Public Foundation. (2018a). International students in Hungarian Higher education institutions. Budapest: Tempus Public Foundation. Retrieved from https://ka.hu/publication/11530/internationalstudents-in-hungarian-higher-education-institutions.

Tempus Public Foundation. (2018b). Stipendium Hungaricum scholarship holders' expectations and attitudes. Budapest: Tempus Public Foundation. Retrieved from https://tka.hu/docs/palyazatok/ stipendium_hungaricum_scholarship_holders_expectations_and_attitudes_web1902051556.pdf.

Tempus Public Foundation. (2020). Measuring the economic impacts of inbound higher education mobility. Budapest: Tempus Public Foundation. Retrieved from https://tka.hu/kiadvany/14367/measuring-theeconomic-impacts-of-inbound-higher-education-mobility. 
UNESCO. (2014). Higher education in Asia: Expanding out, expanding up - the rise of graduate education and university research. UNESCO Institute for Statistics. Retrieved from http://unesdoc.unesco.org/ images/0022/002275/227516e.pdf.

UNESCO. (2019). Global flow of tertiary-level students. Retrieved October 5, 2020, from UNESCO Institute for Statistics: http://uis.unesco.org/en/uis-student-flow.

Wit, H., Hunter, F., Howard, L., \& Egron-Polak, E. (2015). Internationalisation of higher education study. European Parliament's Committee on Culture and Education. Retrieved from http://www.europarl. europa.eu/RegData/etudes/STUD/2015/540370/IPOL_STU(2015)540370_EN.pdf.

\section{Conference paper:}

Dobos, G. (2017). Overview of the Stipendium Hungaricum scholarship programme. Presentation presented at the International conference of Stipendium Hungaricum operational partners, Budapest, Hungary. Retrieved from http://www.tka.hu/international-programmes/8835/presentations.

Yavaprabhas, S. (2009). ASEAN higher education area. Presentation at 2009 World Conference on Higher Education, Macao SAR, PR China. Retrieved from http://www.unescobkk.org/fileadmin/user_upload/ apeid/workshops/macao08/presentations/1-p-1-3-pp.pdf.

Open Access. This is an open-access article distributed under the terms of the Creative Commons Attribution-Non Commercial 4.0 International License (https://creativecommons.org/licenses/by-nc/4.0/), which permits unrestricted use, distribution, and reproduction in any medium for non-commercial purposes, provided the original author and source are credited, a link to the CC License is provided, and changes - if any - are indicated. 